11 per cent of the boys and 12 per cent of the girls who had been evacuated mentioned the day of evacuation or that of the outbreak of war. ' On the other hand, a very large number voted for the day on which they sat for the junior scholarship examination.

Asked to continue a story which began, "There was a loud bang, Pat's heart beat fast," the boys tended towards adventure stories not necessarily connected with the War, girls to air-raid stories.

To the question, "In what period of history would you have preferred to live ?", the majority answered "The present time", and the surprising reason given was, "Because it's more comfortable." A significant number of girls chose a period in which they could wear a picturesque dress.

A free-association test, in which the significant words were "bang, ship, enemy aeroplane, shell", showed a strong war connexion with 'enemy' and 'bang', and it is interesting to note that 'shell' often evoked associations with the sea-shore.

Generally, the investigation showed that the War has had a considerable but not an overwhelming effect on the minds of children.

The impression which the conference as a whole has left on the mind of the writer of this review of its work is that the future of any successful approach to world unity lies in the hands of the teachers, and primarily in the hands of those responsible for the training of our youth below the age of fourteen; that we must rid ourselves of the delusion that there is a ladder of education with the primary school on the lowest rung, and the university on the topmost, and must realize that by far the most important years of education are those passed in our primary and senior schools, and that what happens in later stages is a divergence, rather than a climb; that there is an urgent need for the raising of the status and for the broadening of the training of those destined to become teachers in elementary schools; that the education of such teachers should not be regarded as ending with their period of training, but that every encouragement should be given to their making contacts with the world of thought which lies outside their school ; that it is a desirable thing to teach school subjects from a point of view wider than that of mere nationalism, but that such knowledge must be exact, and must, moreover, be informed by spiritual forces supplied, indirectly, in the home as well as in the school; forces, too, which the teacher must experience in his own home and college ere he can make their influence felt by those whom he is later called upon to teach; that the council is fully alive to these considerations; and that the council will be on the high road to success if its subsequent deliberations are informed with as much knowledge backed with as high an enthusiasm as was shown at its inaugural meeting.

\title{
ESKIMO OF LABRADOR*
}

T the course of the Rawson-MacMillan Subarctic Expedition of the Field Museum (1927-28), Dr. W. Duncan Strong secured a large series of measurements and observations of living Labrador Eskimo and a small group of Montagnais-Naskapi Indians. When obvious mixed bloods and sub-adults are eliminated, the numbers were 137 Eskimo (58 males, 79 females) and 18 Indians (11 males, 7 females). Labrador Eskimo skeletons were also obtained, including thirty-two measurable skulls (17 males, 15 females), many with associated skeletal parts. Measurements made by Shapiro, Boas, Pittard, Duckworth and others have been added in this study. An unusual series is thus made available, comprising (1) an old stone grave series, pre-white, and earlier than 1770 ; $(2)$ a mid-nineteenth century grave series (early Mission period); and (3) racent living (1880-1928).

The material is drawn. from the Eskimo of the north-east coast of Labrador, a remnant of a population once extending to the Gulf of the St. Lawrence. While the influence of the Moravian Mission has been directed to the preservation of Eskimo culture and habits, adoption of Caucasian types of food appears to have introduced modifications of physique, especially in reduction of stature and in general bodily habit of fat.

In the investigation of the Eskimo of Labrador, the evidence of physical character must be invoked to

* Anthropometric Observations on the Eskimos and Indians of Labrador. By T. Dale Stewart. Material and Data collected by William Duncan Strong. (Anthropological Series, Vol. 31, No. 1) (Publication 462). Pp. 164+16 plates. (Chicago: Field Museum of (Publication 462). Pp. $164+16$ plates. aid in the elucidation of the archæological question. Briefly and in very general terms, the archæological problem is to determine the relation in the cultural sequence of pre-Thule, the Dorset and Thule cultures, and recent Eskimo. The evidence of physical anthropology is subject to very definite limitations, not least owing to the absence of skeletal material to be assigned to the Dorset culture.

It would appear that the culture of the Labrador Eskimo was most closely related to that distributed over the central Arctic, but retained more of the Thule culture than has survived in the central regions proper (T. Mathiassen). The Thule culture in the eastern Arctic is present only on pre-contact sites, except for a group on Southampton Island. Although Thule is considered to be the original Eskimo culture of the eastern Arctic, evidence has been presented suggesting that Thule may have been preceded by the Dorset people, though possibly in some places contemporaneous (D. Jenness).

In north-eastern Labrador evidence has been found of an earlier stone culture with Eskimo-like stone ulus, ground slate points and chipped scrapers. It contains almost nothing of the bone, antler, ivory and steatite artefacts characteristic of Thule, Dorset, and Labrador Eskimo (W. D. Strong); and this leads to the suggestion that the Eskimo cannot have been in Labrador for more than four hundred years.

By fitting ethnological detail into this succession of eastern Arctic cultures extending back into the prehistoric, several theories of Eskimo origin and migrations have been formulated, in which the crucial difference is the position to be assigned to 
the Caribou Eskimo of the interior, west of Hudson Bay. These people, in the view of $K$. Birkett. Smith, are a relatively unchanged remnant of the population from which all other Eskimo arose, while Matthiassen regards Thule as the original Eskimo culture and the first to spread eastward over the Arctic coast of America. D. Jenness, on the other hand, has recently put forward the suggestion of a triple division of the present-day Eskimo of Canada in which the natives of the Mackenzie River delta descend from old Thule people who migrated from Alaska to the eastern Arctic a thousand or more years ago, dropping colonies on the way; a second division on the Barren Grounds behind the Hudson, the inland Eskimo, survivors of the primitive Caribou; and descendants of the Eskimo who, about A.D. 1200, flowed out of the inland 'reservoir' and occupied the whole coast-line from Coronation Gulf to Labrador, overwhelming the earlier coast dwellers.

On the grounds of cultural succession, it seems best to assume two reservoirs of population at the beginning of the Christian era, one in Alaska and one in the central Arctic, which must once have been united, presumably before the development of the earliest known culture in the west, the old Bering Sea culture.

Hence it follows that for interpretation of the Labrador physical type comparison with $(a)$ the "Old Igloo" (Birnirk) type from Point Barrow, the oldest known, which has been identified by Hrdlička ; (b) the Thule; and (c) the Dorset physical types is an essential. Unfortunately, as already mentioned, the Dorset type is unknown, while the Thule type was identified only recently (Fischer-Möller, 1937).

The indications of comparative study of the measurements as a whole are that the Labrador skull is small. Metrically, Greenland bears the closest resemblance to Labrador. The main physical changes indicated in a comparison of the old stone grave material and that of the recent grave series is that, as compared with the pagans, the Christians have smaller and shorter heads with longer and narrower faces, relatively higher orbits and relatively narrower alveolar arches. It is uncertain whether the nose has changed. Stature reconstructed from the measurement of the long bones is as follows: old stone graves, 161.4 (male), $150 \cdot 3$ (female); recent graves, $161 \cdot 2$ (male), $149 \cdot 8$ (female). This suggests that Eskimo stature has decreased in Labrador since the eighteenth century, a conclusion borne out by the findings on the living. Two stature groups can be distinguished : (1) a low-statured group averaging in the males about $160-162 \mathrm{~cm}$., found chiefly in the east (Labrador, southern Greenland), and (2) a high-statured group, 164-166 cm., in the males, found chiefly in the west, but also among the Thule people in the east.

To sum up, it may be said that these data on the prehistoric Labrador Eskimo establish more firmly the fact that the physical type represented is much the same as that predominant in Greenland; it differs materially from that of the western longheads (Old Ingloo). Also it contrasts with that of the Thule. Assuming that Labrador was populated originally by Thule people, the type did not survive. Whether the Labrador and Greenland type was de. rived from a mixture of the Thule and Dorset peoples, or a representative of the latter alone, cannot be decided until the Dorset type is identified.
SEVENTY YEARS AGO

NAtUre, vol. I, April 28, I870

\section{Early Torpedoes}

THE first of a series of articles on "The Science of Explosives as applied to Warlike Purposes" appears, and deals particularly with history of the use of explosives as floating or submarine mines and torpedoes.

The earliest form of marine mine appears to have been the 'explosion ship' used by the Dutch to destroy a boom or boat-bridge constructed across the Scheldt in 1585 . Several flat-bottomed vessels loaded with gunpowder were sent against the boom, exploding when they reached it. A development of this was the 'floating petard' used by the English during operations in Rochelle in 1628; this consisted of a sheet-iron case filled with powder which was exploded by a match-lock mechanism set off by contact with an obstacle.

An American, Robert Fulton, seems to have been the first to use the term 'torpedo'. His device consisted of a metal vessel holding about $100 \mathrm{lb}$. of gunpowder and fitted with clockwork to release a flint-lock at a determined time. The machine was partly encased in cork so that it was a little heavier than water, and was attached by a line to a box float. The torpedoes were carried in harpoon boats, and connected by long lines with harpoons fired from small guns at the ship to be attacked. If the harpoon was successfully planted, the torpedo was drawn into the water by the line, the clockwork firing mechanism released, and the torpedo exploded by the time it had drifted near the vessel attacked. Demonstrations with these torpedoes were carried out before English naval authorities in 1805. A diagram of a torpedo and its harpoon is printed.

Extensive use was made of mines, or torpedoes as they were called, in the American Civil War, both mechanical and electrical means of ignition being used.

\section{Legislation and Nature}

"THE effect of Legislation upon Nature is one of those far-reaching subjects which men are only just beginning to investigate in a practical spirit. . . . Neither directly nor indirectly, in fact, can we touch Nature by our laws, without beginning a new chain of causes, the end of which we cannot foresee."

Mr. E. Goadby is discussing an item in the Budget introduced by Mr. Lowe. "The freedom of firearms from taxation affects their number in any district, the number of guns determines the number of small birds, and the number of our small birds affects the immunity of our fields from grasshoppers, cricketmoles, beetles, locusts, slugs, etc. Mr. Lowe was concerned for the security of life, for the prevention of early quasi-poaching habits, but his $1 l$. tax may effect a revolution all the same."

Another topic also discussed by Mr. Goadby is the rating of woods and plantations. He refers to the incidence of insects in relation to trees, and concludes: "Disafforesting threatens to become as common in the nineteenth as enclosuring was in the sixteenth century. Are we wise to hasten it?"

This issue of Nature completes the first volume of twenty-six weekly issues, price $4 d$. each. The volume includes 558 pages of text and 110 pages of advertisements. 